\title{
A PROPÓSITO DE UNA MAGDALENA DEL ESCULTOR VALLISOLETANO PEDRO DE ÁVILA EN SEVILLA
}

\section{ABOUT A MAGDALENE OF VALLISOLETANO SCULPTOR PEDRO DE ÁVILA IN SEVILLE}

\author{
Javier Baladrón Alonso \\ Universidad de Valladolid. España \\ ORCID: 0000-0001-7548-2962 \\ balilla19@hotmail.com
}

A mediados del año 2017 se dio a conocer en una exposición celebrada por Isbilya Subastas en Sevilla una buena escultura de Santa María Magdalena que fue asignada al excelso escultor granadino José de Mora. El presente artículo pretende rechazar dicha atribución y formular otra a favor del maestro vallisoletano Pedro de Ávila, a quien a todas luces corresponde su paternidad dada la completa semejanza con su estilo.

Palabras clave: Barroco; escultura; Pedro de Ávila; Sevilla; siglo XVIII.

In the middle of the year 2017, a good sculpture of Saint Mary Magdalene was published by an exhibition held at Isbilya Subastas (Seville). It was attributed to the sublime Granadan sculptor José de Mora. The current paper aims to reject such attribution as well as indicating another one in favour of the Vallisoletano master Pedro de Ávila. Certainly, the authorship of this sculpture can be connected with this author due to the existence of complete similarities with his style.

Keywords: Baroque; sculpture; Pedro de Ávila; Seville; $18^{\text {th }}$ century.

En el mes de marzo de 2017 Isbilya Subastas inauguró una nueva sala en Sevilla $^{1}$, y para celebrarlo organizó una exposición de escultura barroca española titulada "La imagen religiosa y el triunfo de la madera" en la que sobresalieron piezas de autores tan célebres como Juan Martínez Montañés (1568-1649), Pedro de Mena (1628-1688), José de Mora (1642-1724) o Luisa Roldán "La Roldana" (1652-1706). Entre el numeroso elenco de obras que componían la muestra, todas

${ }^{1} \mathrm{https} / /$ /arsmagazine.com/isbilya-inaugura-sede-con-una-exposicion-de-esculturabarroca-espanola/ (Consultado el 16-4-2018). 
ellas de temática religiosa y fechadas entre los siglos XV-XVIII, se encontraba una buena imagen de la Magdalena Penitente (Figura 1) que, atribuida al granadino José de Mora, es obra indubitable de Pedro de Ávila (1678-1755)², el escultor más descollante del foco vallisoletano durante el primer tercio del siglo XVIII, y de quien, por cierto, recientemente han salido a la venta otras dos esculturas en Madrid ${ }^{3}$.

La representación de la Magdalena, prototipo de mujer arrepentida y penitente, fue una de las predilectas de Pedro de Ávila, puesto que la efigió en numerosas ocasiones. Así, además de esta obra que presentamos, conocemos al menos otras cuatro esculturas: las que talló para la catedral (1714) y para el oratorio de San Felipe Neri (1720) (Figura 2) de Valladolid; y otras dos que se le atribuyen en la fachada de la iglesia de Santa María Magdalena de Valladolid y en la parroquial de Matapozuelos (Valladolid) (ca. 1724-1725). Cada una de estas cuatro piezas es totalmente diferente tanto desde el punto de vista formal como del iconográfico, e incluso están realizadas en diferentes materiales, ya que a las talladas en madera se suma la pétrea de la fachada de la citada iglesia de la Magdalena. La escultura en piedra no fue una de las especialidades de la escuela vallisoletana dada la falta de maestros peritos en su talla, si bien en esta época se llevaron a cabo diversas empresas que requirieron su labra, como por ejemplo las estatuas que engalanan la fachada de la catedral de Valladolid, realizadas por Pedro Bahamonde (1707-1748) y Antonio de Gautúa (1682-1744)4; y las esculturas de la fachada del monasterio de la Santa Cruz de las Comendadoras de Santiago de la misma ciudad, las cuales se atribuyen al propio Pedro de Ávila 5

El interés de la pieza que ahora damos a conocer es muy grande puesto que, además de mostrar un tipo iconográfico radicalmente distinto a todos los que

${ }^{2}$ Sobre Pedro de Ávila, BALADRÓN ALONSO, Javier: Los Ávila: una familia de escultores barrocos vallisoletanos. Tesis doctoral, Universidad de Valladolid, 2016. Se puede consultar online en https://www.academia.edu/31893548/Los_\%C3\%81vila._Una_familia_de_escultores_barrocos_vallisoletanos. Recientemente hemos atribuido otra pieza a Pedro de Ávila en la propia ciudad de Sevilla: BALADRÓN ALONSO, Javier: "Mater Dolorosa. La Virgen de los Dolores y la Piedad en la obra del escultor vallisoletano Pedro de Ávila (1678-1755)", Revista Atticus, 35, 2017, pp. 55-64.

${ }^{3}$ En Alcalá Subastas están a la venta dos buenas efigies de San Francisco y Santa Clara. Unos meses antes habían estado expuestas en el comercio de Antigüedades de Carmelo Gómez, en Valladolid. http://www.alcalasubastas.es/es/subastas/60-64750/pedro-de-avila-valladolid-1678-1742-santa-clara-y-san-francisco-esculturas-en-madera-tallada-policromada-y-estofada-circa-1720 (Consultado el 16-4-2018).

${ }^{4}$ GARCÍA CHICO, Esteban: Documentos para el estudio del arte en Castilla. 2, Escultores. Valladolid, 1941, pp. 386-387.

${ }^{5}$ MARTÍN GONZÁLEZ, Juan José y DE LA PLAZA SANTIAGO, Francisco Javier: Catálogo Monumental de la provincia de Valladolid. Tomo XV. Monumentos religiosos de la ciudad de Valladolid (2 ${ }^{a}$ parte). Valladolid, 2001, p. 329. 
utilizó, reproduce el modelo popularizado por Pedro de Mena, y cuyo ejemplar más descollante es la Magdalena Penitente $(171 \mathrm{~cm}$ ) (Figura 3) que esculpió en 1664 para la desaparecida Casa Profesa de Madrid ${ }^{6}$ y que actualmente se encuentra cedida por el Museo del Prado en el Museo Nacional de Escultura de Valladolid. El éxito de esta escultura, que resulta ser la quintaesencia de su estilo refinado y melancólico, se debió, en palabras de Gila Medina, a que "cumplía plenamente los deseos de la Compañía en orden a que sus trabajos fuesen lo suficientemente útiles y eficaces para su labor evangelizadora y catequética, y en este caso la Magdalena era un modelo excepcional, dado que tras una juventud fácil, tras su encuentro con Cristo y sincero arrepentimiento se convertirá en su más fiel discípula, siguiéndole hasta incluso después de su Crucifixión"7. La excelencia de la imagen es tal que llevó al poeta asturiano Francisco Antonio de Bances (16621704) a alabar "la habilidad de Mena para transformar la materia en una forma con aspecto vivo"s.

Desde el mismo momento de su ejecución, la Magdalena de los jesuitas madrileños causó tal asombro y admiración que se solicitaron diversas copias y reproducciones, algunas de las cuales corrieron a cargo del propio Mena. De esta manera la iconografía se difundió con rapidez por buena parte del territorio español. Sin embargo, hay que incidir en el hecho de que a Mena se debe la popularización del modelo, sin duda debido a su altísima calidad técnica y a su fuerza y viveza espiritual, pero no su creación. Este honor le pertenece a Gregorio Fernández (1576-1636), el gran maestro de la escuela barroca castellana, que es a quien se atribuye la Magdalena del monasterio de las Descalzas Reales de Madrid9 (ca. 1620-1629) (Figura 4), considerada el prototipo de esta iconografía. Señala Xavier Bray que cuando "Mena viajó a Toledo en 1663 para tallar su célebre San Francisco de Asís en éxtasis para la catedral, muy probablemente visitó Madrid con el objetivo de pedir al rey un puesto como escultor de la corte. Fue quizás en esta fecha cuando recibió este encargo de los jesuitas de Madrid y es probable

${ }^{6}$ Tras la Pragmática Sanción de 1767 en que se dictaba la expulsión de los jesuitas de todos los dominios de España, la Casa Profesa pasó a poder de los oratorianos de San Felipe Neri que la habitarían hasta la Desamortización. Con posterioridad la escultura marchó al convento de las Salesas Reales de la Visitación, al Museo de la Trinidad y finalmente al Museo del Prado, institución que durante mucho tiempo, e incluso hoy en día, la tiene cedida en depósito en el Museo Nacional de Escultura de Valladolid. GILA MEDINA, Lázaro: Pedro de Mena escultor: 1628-1688. Madrid, 2007, p. 124.

7 Ibidem.

8 BRAY, Xavier: "23. Pedro de Mena. María Magdalena Penitente", en BRAY, Xavier: Lo sagrado hecho real. Pintura y escultura española 1600-1700. Madrid, 2010, p. 151.

9 GÓMEZ MORENO, María Elena: Ars Hispaniae. Escultura del siglo XVII. T. XVI. Madrid, 1963, p. 74. Ya Orueta había sugerido con anterioridad que la Magdalena de las Descalzas Reales pudo haber sido el modelo que tomó prestado Mena. ORUETA, Ricardo: La vida y la obra de Pedro de Mena. Madrid, 1914, p. 180. 
que durante su visita también viera una escultura anterior de la Magdalena penitente, fechada en el decenio de 1620 en el monasterio de las Descalzas Reales, que se ha atribuido de manera no definitiva a Gregorio Fernández"10. Ya Orueta aludió acertadamente a que "si la creación del tipo no se puede asignar a Mena, hay que reconocer que lo ha mejorado y ha encarnado en él su propia inspiración"11.

Resulta llamativo el hecho de que ni Gregorio Fernández, ni sus oficiales y discípulos volvieran a representar a la santa de esta manera. Tan solo se podría reseñar la destruida Magdalena de la iglesia de San José de Gijón que se atribuía a Luis Fernández de la Vega (1601-1675), discípulo asturiano de Fernández ${ }^{12}$. La fama que alcanzó esta iconografía en tierras castellanas, en general, y vallisoletanas, en particular, se debió fundamentalmente a la copia de la Magdalena (162 $\mathrm{cm}$ ) de Mena que poseyó el colegio jesuita de San Ignacio de Valladolid (Figura 5), y que fue donada por doña Magdalena de Pimentel, marquesa de Viana, en su testamento de $1702^{13}$. Dicha efigie de los jesuitas vallisoletanos aún no ha logrado una atribución definitiva. Señala Hernández Redondo que "se han apuntado las más diversas probabilidades: desde que fuera una obra italiana traída por los jesuitas en el siglo XVIII [...] hasta su atribución a Gregorio Fernández o a un próximo seguidor suyo" 14 . Después de habérsela asignado a maestros tan dispares como Gregorio Fernández $7^{15}$, Pedro de Ávila ${ }^{16}$ o Tomás de Sierra, es la opción de este último la que en la actualidad recoge mayores consensos ${ }^{17}$.

Antes de continuar, me gustaría llamar la atención sobre el curioso fenómeno de propagación que llevaron a cabo los jesuitas con determinados tipos iconográficos existentes en sus centros madrileños -la Casa Profesa y el colegio Imperial-, los cuales posteriormente se veían replicados en otros establecimientos que la Compañía de Jesús tenía repartidos por el país. Además del caso de la Magdalena de Pedro de Mena, es significativo el éxito que alcanzó el Calvario del Cristo de la Buena Muerte del colegio Imperial de Madrid, cuyas efigies -Virgen Dolorosa,

10 BRAY, Xavier: Lo sagrado hecho real..., op. cit., p. 151.

${ }^{11}$ ORUETA, Ricardo: La vida y la obra..., op. cit., p. 180.

12 Ibidem, p. 179.

${ }_{13}$ Hoy en día se conserva en el mismo templo, ya que tras la expulsión de los jesuitas la iglesia pasó a acoger la parroquia de San Miguel y San Julián. MARTÍN GONZÁLEZ, Juan José y URREA FERNÁNDEZ, Jesús: Catálogo Monumental de la provincia de Valladolid. Tomo XIV. Monumentos religiosos de la ciudad de Valladolid (1 $1^{a}$ parte). Valladolid, 1985, pp. 115 y 133.

${ }^{14}$ HERNÁNDEZ REDONDO, José Ignacio: “28. Magdalena. Anónimo. Escuela castellana", en VV. AA.: Pedro de Mena y Castilla (Catálogo de exposición). Valladolid, 1989, p. 76.

${ }^{15}$ ORUETA, Ricardo: La vida y la obra..., op. cit., p. 178.

16 MARTÍN GONZÁLEZ, Juan José: Escultura barroca castellana. Madrid, 1959, p. 165.

17 Ibidem. 
San Juan y la Magdalena-, con la excepción del Cristo (Juan de Mesa, 1621), fueron también obra de Pedro de Mena. Así, los jesuitas de Oviedo (colegio de San Matías, actual iglesia de San Isidoro) y de Valladolid (colegio de San Ignacio, actual iglesia de San Miguel y San Julián) emularon el citado Calvario madrileño, y además por el mismo procedimiento: a un Cristo cronológicamente más antiguo le añadieron las esculturas de la Virgen y San Juan a los lados, y la Magdalena al pie de la cruz. Mientras que las copias vallisoletanas están atribuidas a Juan Alonso de Villabrille y Ron $(1663-1732)^{18}$, las de Oviedo no poseen una asignación concreta.

Retomando el tema que nos concierne, a partir de estas dos "Magdalenas jesuíticas", el modelo de Mena se propagó hasta la extenuación por los territorios de las actuales comunidades de Madrid y de Castilla y León. También se contabilizan numerosos ejemplares por el norte peninsular (Galicia ${ }^{19}$, Asturias ${ }^{20}$, Cantabria $^{21}$ o Navarra ${ }^{22}$, mientras que en Andalucía el impacto fue mínimo ${ }^{23}$, pudiéndose reseñar el de la iglesia de Santa María Magdalena en Granada ${ }^{24}$.

En la ciudad de Valladolid podemos citar las dos conservadas en la iglesia de Santa María Magdalena, la del museo del convento de Santa Isabel, o las desaparecidas del convento de las Descalzas Reales y del monasterio de San Joaquín y Santa Ana. Desconocemos la relación que mantuvo Pedro de Mena con este último convento, más allá de que pertenece al Císter, la misma orden en la que ingresaron sus dos hijas mayores, Andrea y Claudia ${ }^{25}$, pero el caso es que en él

${ }^{18}$ URREA, Jesús: "Villabrille y Ron y la capilla de la Buena Muerte, de San Ignacio de Valladolid", Boletín del Museo Nacional de Escultura, 11, 2007, pp. 22-29.

19 Son reseñables las conservadas en las iglesias de Santa María de La Coruña y de San Bartolomé de Pontevedra -en origen colegio jesuítico--. LUNA MORENO, Luis: "En torno a Pedro de Mena y la escultura castellana", en VV. AA.: Pedro de Mena..., op. cit., p. 10. También puede reseñarse la presente en uno de los retablos colaterales de la capilla del Cristo de la catedral de Orense.

${ }^{20}$ Se pueden citar los casos de las Magdalenas de la colegiata de Santa María de Tanes, atribuida a Antonio Borja (1660-1730), o las dos de la catedral de Oviedo, una en la capilla de la Magdalena y otra en la girola, obra esta última de José Bernardo de la Meana (1715-1790). RAMALLO ASENSIO, Germán: Escultura barroca en Asturias. Oviedo, 1985, pp. 331, 428 y 472.

${ }^{21}$ Existe un ejemplar de procedencia vallisoletana o riosecana en el santuario de Nuestra Señora de Las Caldas en Las Caldas de Besaya.

${ }^{22} \mathrm{El}$ escultor navarro afincado en la corte Roque Solano talló una para la iglesia de Santa María de la localidad de Viana. FERNÁNDEZ GRACIA, Ricardo: "Los géneros escultóricos", en FERNÁNDEZ GRACIA, Ricardo (coord.): El arte del barroco en Navarra. Pamplona, 2014, p. 240.

${ }^{23}$ GILA MEDINA, Lázaro: Pedro de Mena..., op. cit., p. 125.

${ }^{24}$ BRAY, Xavier: Lo sagrado hecho real..., op. cit., p. 151.

${ }^{25}$ Concretamente en el monasterio del Císter de Málaga. GILA MEDINA, Lázaro: Pedro de Mena..., op. cit., p. 51. 
existió una efigie de Santa María Magdalena donada por el propio artífice granadino. La generosidad del escultor no se quedó ahí puesto que además regaló una "pequeña imagen", de la que desconocemos su identidad, así como sendos bustos de Ecce y Dolorosa, de los que tan solo se conserva este último, desconociéndose el paradero del resto ${ }^{26}$.

También hemos de considerar como obra vallisoletana la estupenda Magdalena que Martín González dio a conocer en la igreja de Santa María da Assunção o de Nossa Senhora do Sardão de Bragança (Portugal) (Figura 6) ${ }^{27}$. Fechada a finales del siglo XVII, su autoría se la disputan Juan Antonio de la Peña (ca.16501708) y Juan de Ávila (1652-1702), que a la sazón fueron suegro y padre de Pedro de Ávila.

Por su parte, el ámbito madrileño cuenta con importantes copias y/o réplicas, como una de pequeño tamaño en las Trinitarias Descalzas de San Ildefonso; otras dos que existieron en el convento de Mercedarias Descalzas de don Juan de Alarcón ${ }^{28}$ y en la capilla de Santa Gertrudis de la iglesia de San Martín ${ }^{29}$; y la que preside el retablo mayor de la parroquial de Torrelaguna (Madrid), atribuida a Luis Salvador Carmona (1708-1767), a quien, por cierto, también se adjudica una pequeña y deliciosa copia conservada en el Museo Nacional de Escultura y que en origen perteneció a la capilla del Ángel del convento de Trinitarios Descalzos de Madrid $^{30}$. También de procedencia madrileña es la réplica, un tanto libre, que el escultor navarro, aunque asentado en la corte, Roque Solano (1654-1704) esculpió para la iglesia de Santa María de Viana (Navarra) ${ }^{31}$.

Pedro de Mena, del cual se conocen otras imágenes autógrafas de la Magdalena, como una firmada y fechada en 1677 que procedía de un convento de Madrigal $^{32}$, no se limitó únicamente a representarla según este modelo iconográfico,

${ }^{26}$ Como referimos, en el archivo del monasterio se conserva un documento en el que se cita que Pedro de Mena regaló a la comunidad de monjas bernardas de San Joaquín y Santa Ana cuatro esculturas: Santa María Magdalena, busto de Ecce Homo, busto de Dolorosa y una "pequeña imagen" de la que no se cita su iconografía.

27 MARTÍN GONZÁLEZ, Juan José: La huella española en la escultura portuguesa. Valladolid, 1961, pp. 29-30.

${ }^{28}$ Fototeca del Patrimonio Histórico, $N^{\circ}$ 07748_B. http://www.mcu.es/fototeca_patrimonio/.

${ }^{29}$ LUNA MORENO, Luis: "En torno a Pedro de Mena y la escultura castellana", en VV. AA.: Pedro de Mena..., op. cit., p. 12.

${ }^{30}$ GARCÍA GAINZA, María Concepción: El escultor Luis Salvador Carmona. Pamplona, 1990, pp. 68 y 85.

31 FERNÁNDEZ GRACIA, Ricardo: "Los géneros escultóricos", en FERNÁNDEZ GRACIA, Ricardo (coord.): El arte del barroco..., op. cit., p. 240.

32 Actualmente se encuentra en paradero desconocido. GÓMEZ MORENO, María Elena: "Pedro de Mena y los temas iconográficos", en VV. AA.: Pedro de Mena..., op. cit., p. 89 . 
sino que creó otro con ligeras variantes. La disposición general del cuerpo es idéntica, tan solo se distingue por el cambio de vestimenta, ya que la estera de palma es sustituida por una túnica de tela que le llega a tapar el hombro izquierdo. Además, la larga melena no le cae por ambos lados del rostro hasta el pecho, sino que tan solo lo hace sobre el hombro izquierdo y hasta la altura de la cintura. La policromía del vestido simula tanto la calidad de la tela como los remendones de la misma. De este modelo conocemos dos imágenes desaparecidas: la que presidió el retablo mayor del convento de las Agustinas de Santa María Magdalena de Alcalá de Henares (Madrid) ${ }^{33}$ y la de la iglesia del barrio de Salamanca de Madrid ${ }^{34}$. A estas hemos de añadir la que perteneció a la colección de Félix Valdés, de Bilbao $^{35}$, que con toda probabilidad sea la que recientemente ha salido a la venta en la casa de subastas Fernando Durán ${ }^{36}$ (Figura 7).

Volviendo a la escultura que nos atañe, desconocemos su procedencia, aunque lo más probable es que lo haga de alguna iglesia o convento de Castilla y León, ámbito para el que mayoritariamente trabajó Pedro de Ávila, si bien también recibió encargos desde otros puntos más distantes como Galicia o Navarra. La presente Magdalena no deja de ser un remedo de la de Pedro de Mena, puesto que no posee ni su dinamismo, ni su vitalidad, ni su acendrado naturalismo, ni tampoco llega a alcanzar su estudio de las calidades, especialmente en la representación de la carne. En definitiva, la gran diferencia es la calidad técnica existente entre Mena y Ávila, y que se observa en detalles como el envaramiento general del cuerpo de la santa o la rigidez con que están compuestos sus cabellos. Así, mientras que en el ejemplar de Mena observamos una caballera suelta muy naturalista y con los mechones individualizados, los cabellos tallados por Ávila están totalmente apelmazados, sin apenas resalte, pegados al cuerpo y unidos entre sí formando amplias y sinuosas guedejas.

María Magdalena es efigiada en un momento de intenso arrobo y meditación ante una cruz que agarra con su mano izquierda, si bien originariamente sostendría un Crucifijo. La otra mano la posa delicadamente sobre el pecho, como conteniendo la respiración ante la contemplación del Crucificado. Figura de pie, con la pierna izquierda adelantada, como en ademán de caminar sobre un paraje ro$\operatorname{coso}^{37}$. Viste una estera de palma que le cubre completamente el cuerpo desde la

${ }^{33}$ LUNA MORENO, Luis: "En torno a Pedro de Mena y la escultura castellana", en VV. AA.: Pedro de Mena..., op. cit., p. 12.

34 Ibidem.

${ }^{35}$ Fototeca del Patrimonio Histórico, No 20748_B. http://www.mcu.es/fototeca_patrimonio/.

${ }^{36} \mathrm{https} / / /$ www.fernandoduran.com/duran/688-atribuido-a-pedro-de-mena-1628-1688. html\#product.info.description (Consultado el 15-4-2018).

${ }^{37}$ En Castilla es frecuente que las Magdalenas, especialmente las de pequeño formato, que irían metidas dentro de escaparates, estuvieran rodeadas de pintorescos paisajes que 
parte inferior del busto hasta los tobillos, dejando tan solo desnudos el torso, los brazos y los pies. La estera se ciñe a la cintura con una ajustada cuerda trenzada sin apenas resalte ni valor plástico, todo lo contrario a lo que ocurre con Mena, quien la esculpe mucho más verosímil. También es perceptible esa diferencia de pericia técnica en la representación de las manos, pues Ávila no las ha modelado con la finura, delicadeza y precisión del maestro granadino. Asimismo, difiere bastante la expresión del rostro, puesto que mientras que Mena la concibe blanda, como si en realidad fuera carne, en la del vallisoletano hay bastante dureza, a lo que hay que sumar el semblante triste que consigue a través del exagerado enarcamiento de las cejas. El rostro es casi una versión expresionista del ejemplar de Mena, el cual se caracteriza por la dulzura con la que están delineados los rasgos faciales, especialmente los ojos, la nariz, los labios, las cejas y la frente. Mantiene la boca entreabierta "como si le faltara aliento, abrumada por la compasión que siente por el sufrimiento de Cristo" 38 . El pelo cae simétricamente a ambos lados del rostro y hasta más abajo de la cintura en largas y onduladas guedejas compactas que evocan tanto su vida eremítica como su feminidad. Grandes mechones le cubren parte de los hombros y de la espalda.

Los motivos para su atribución a favor de Pedro de Ávila son puramente formales, ya que el rostro de la santa presenta todos y cada uno de los estilemas que conforman su "maniera", siendo también característica la manera de agrupar los cabellos tanto por la parte delantera como por la trasera en amplios y sinuosos mechones. La forma en que estos caen por la espalda está tomada de las Inmaculadas de Gregorio Fernández. En cuanto a los rasgos faciales (Figura 8) que determinan el estilo de Ávila y que están presentes en la Magdalena tenemos los siguientes: cabeza rectangular con la parte inferior ligeramente curvada, leve papada y potente mentón. Frente amplia y despejada. Ojos de pasta vítrea con forma almendrada y con un ligero rehundimiento en la parte inferior. Nariz recta, potente, geometrizada, y más ancha en su parte inferior. Tabique nasal ancho y aplastado, aletas levemente pronunciadas, y fosas nasales perforadas para alcanzar mayor grado de verosimilitud. Boca pequeña y entreabierta, con labios muy finos y comisuras pronunciadas. Pómulos ligeramente abultados y con entonaciones rosáceas. Al no ir ataviada con una vestimenta convencional sino con rígidas hojas de palmera no hay ocasión para que Ávila disponga uno de los elementos claves de su plástica: el paño a cuchillo o pliegue "berninesco".

evocaran su vida ermitaña. Estos están formados a base de rocas, árboles, riachuelos, pequeñas oquedades o grutas, y diversos animalillos como palomas, serpientes, ranas, etc. Además, en ocasiones pueden figurar sobre el suelo rocoso algunos de sus atributos, caso de la calavera o incluso el bote de perfumes. Es frecuente encontrar estas mismas peanas en las representaciones barrocas de San Juan Bautista Niño.

${ }^{38}$ BRAY, Xavier: Lo sagrado hecho real..., op. cit., p. 150. 
Todos estos estilemas que acabamos de referir son los propios de la segunda etapa del escultor, que se inicia hacia el año 1707, fecha en la que regresó de un hipotético viaje formativo a Madrid. Al no contar con ningún dato más es complicado establecer una cronología precisa, por lo que habría que fecharla en el amplio lapso de tiempo que media entre 1707-1740, año este último en el que el escultor quedó ciego. Aunque se trata de una escultura de cierta calidad, la rudeza con que están labradas las manos, el envaramiento general de la imagen y la poca definición que acusan las facciones del rostro y los cabellos nos lleva a pensar en que pudo existir bastante labor de taller.

Fecha de recepción: 21 de mayo de 2018

Fecha de aceptación: 5 de febrero de 2019 


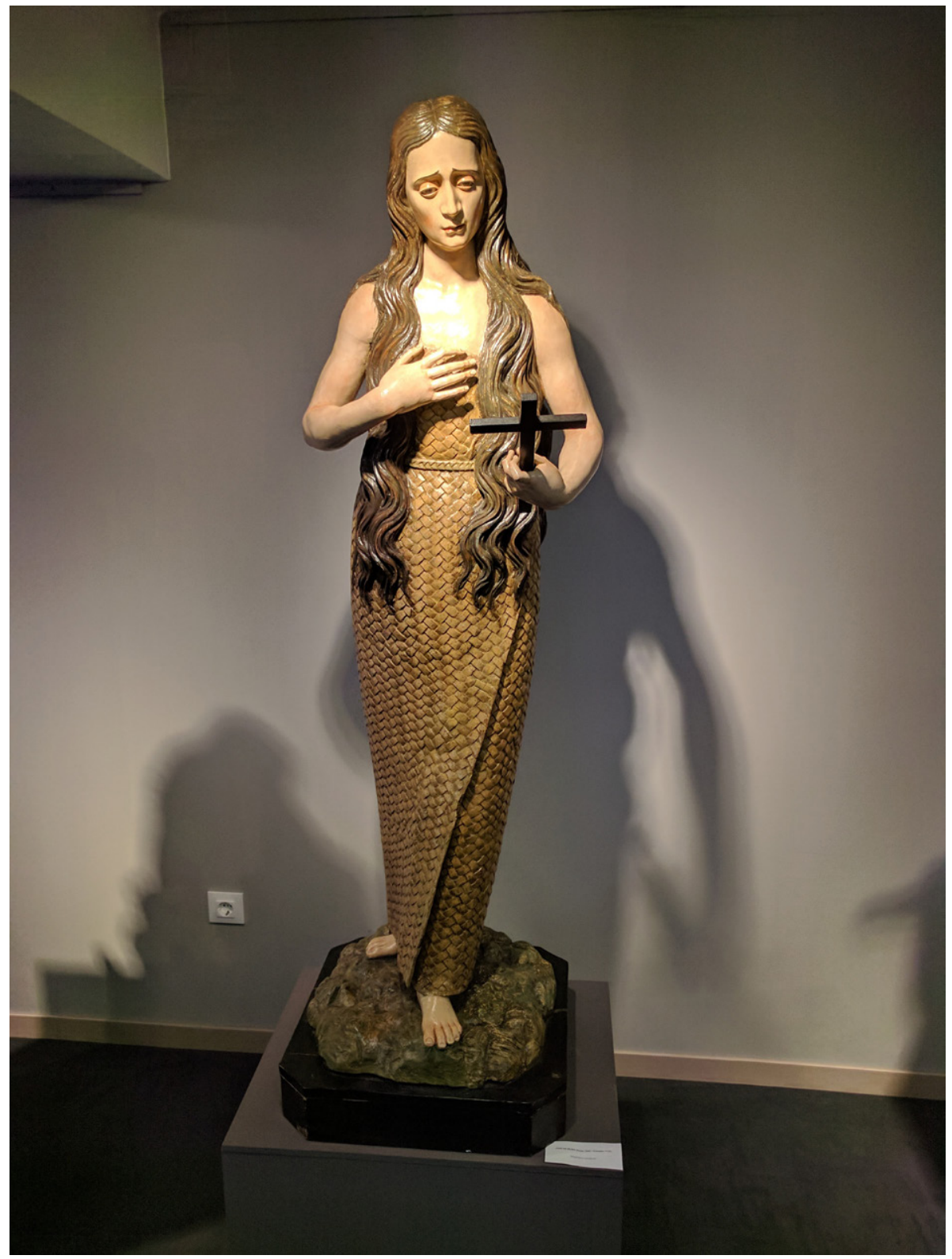

Figura 1. Atribuida a Pedro de Ávila, Magdalena penitente, hacia 1707-1740, Isbilya Subastas, Sevilla. (C) Daniel Puertas. 


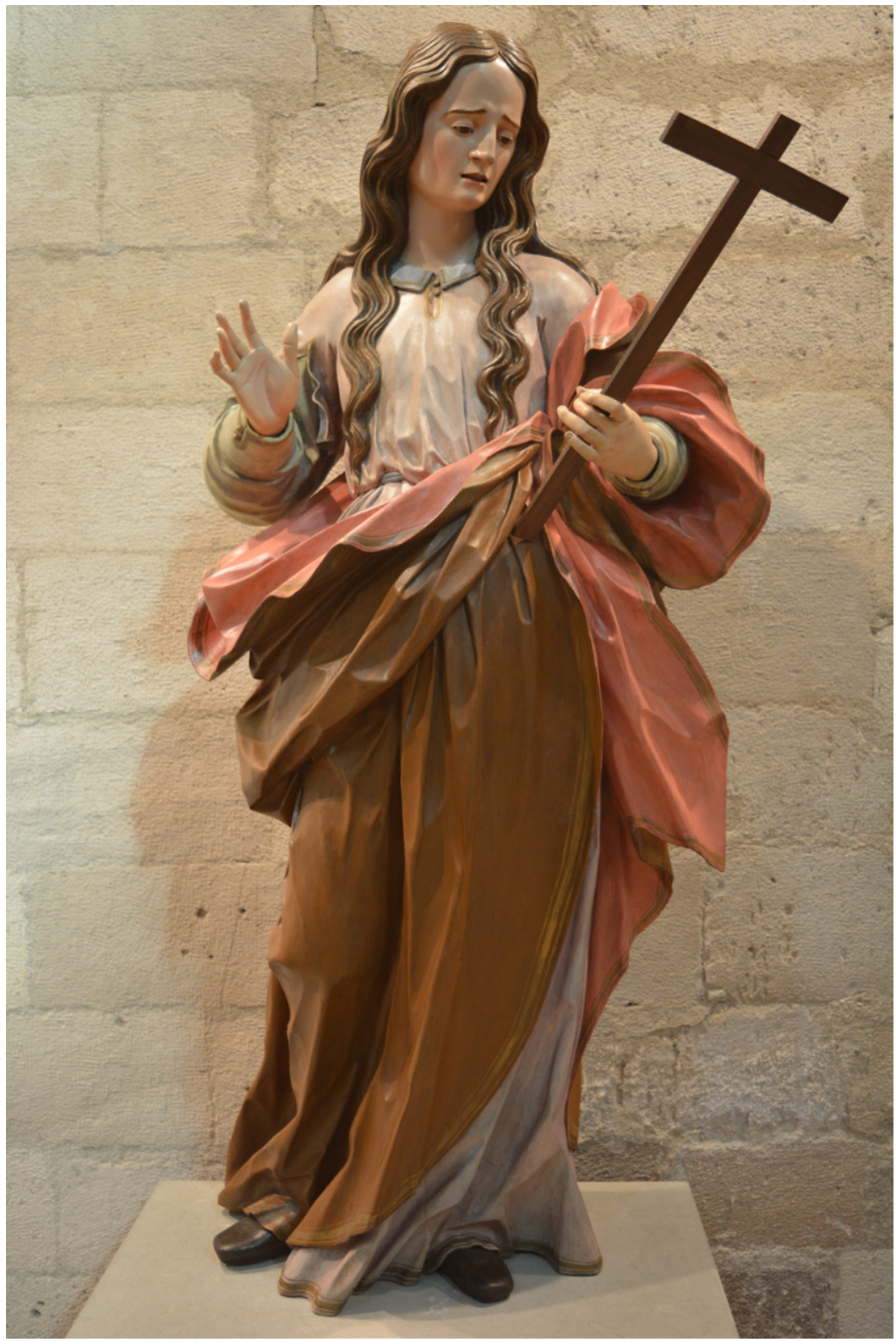

Figura 2. Pedro de Ávila, Magdalena penitente, 1720, Museo Diocesano y Catedralicio, Valladolid. 


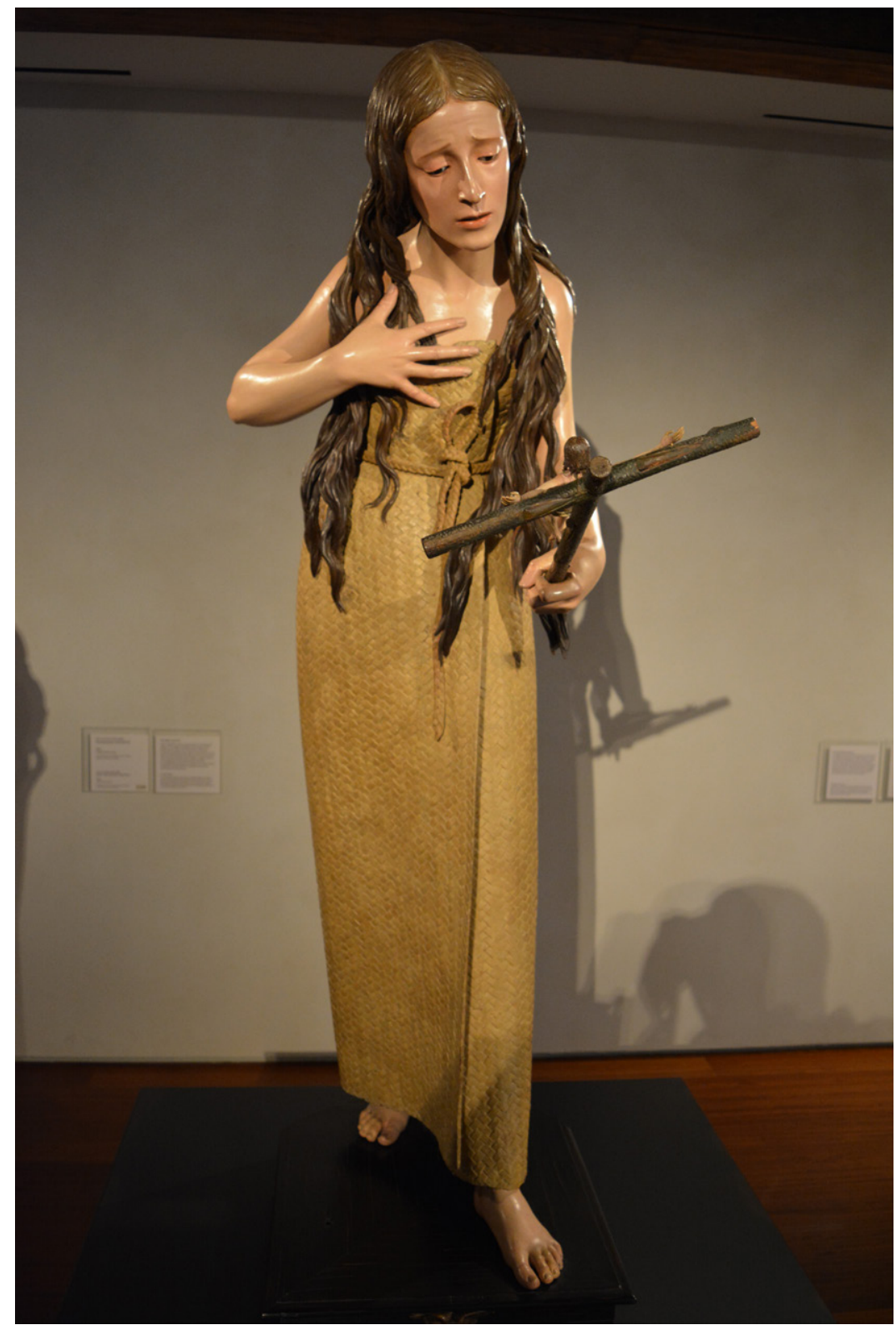

Figura 3. Pedro de Mena, Magdalena Penitente, 1664, Museo Nacional de Escultura, Valladolid. 


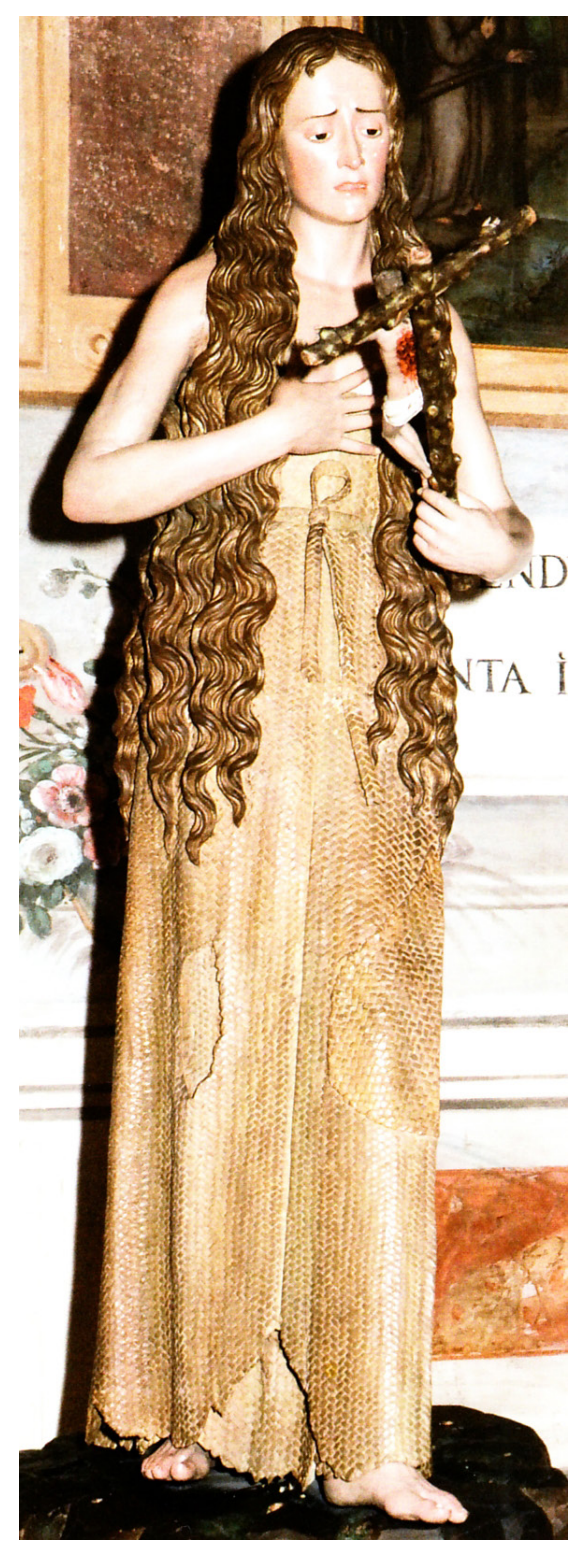

Figura 4. Atribuida a Gregorio Fernández, Magdalena penitente, hacia 1620-1629, monasterio de las Descalzas Reales, Valladolid. C Patrimonio Nacional. 


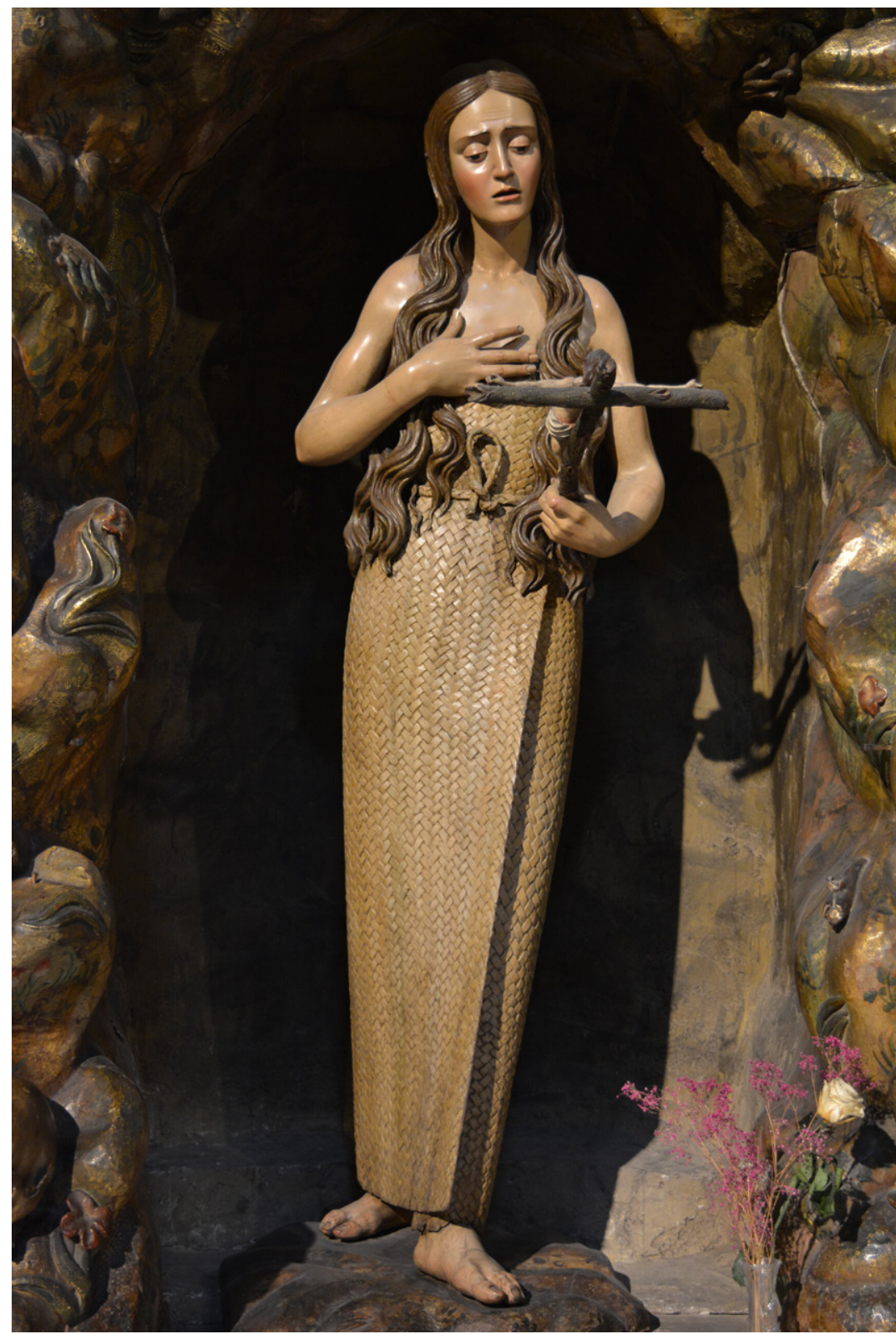

Figura 5. Atribuida a Tomás de Sierra, Magdalena penitente, finales del siglo XVII, iglesia de San Miguel y San Julián, Valladolid. 


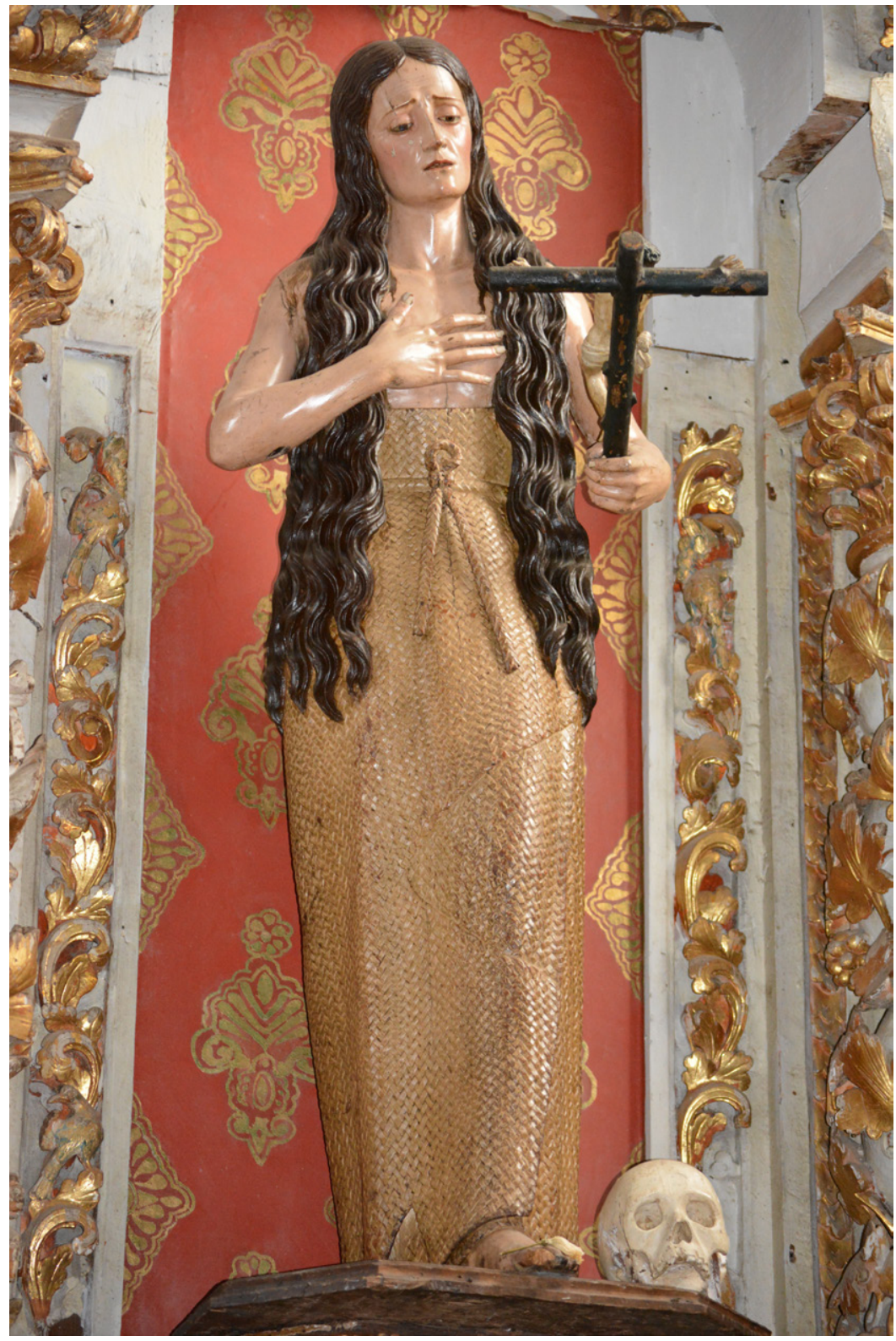

Figura 6. Atribuida a Juan de Ávila y/o Juan Antonio de la Peña, Magdalena penitente, finales del siglo XVII, igreja de Santa María da Assunção, Bragança. 
Figura 7. Pedro de Mena, Magdalena penitente, Casa de Subastas Fernando Durán, Madrid. (C) Casa de Subastas Fernando Durán.
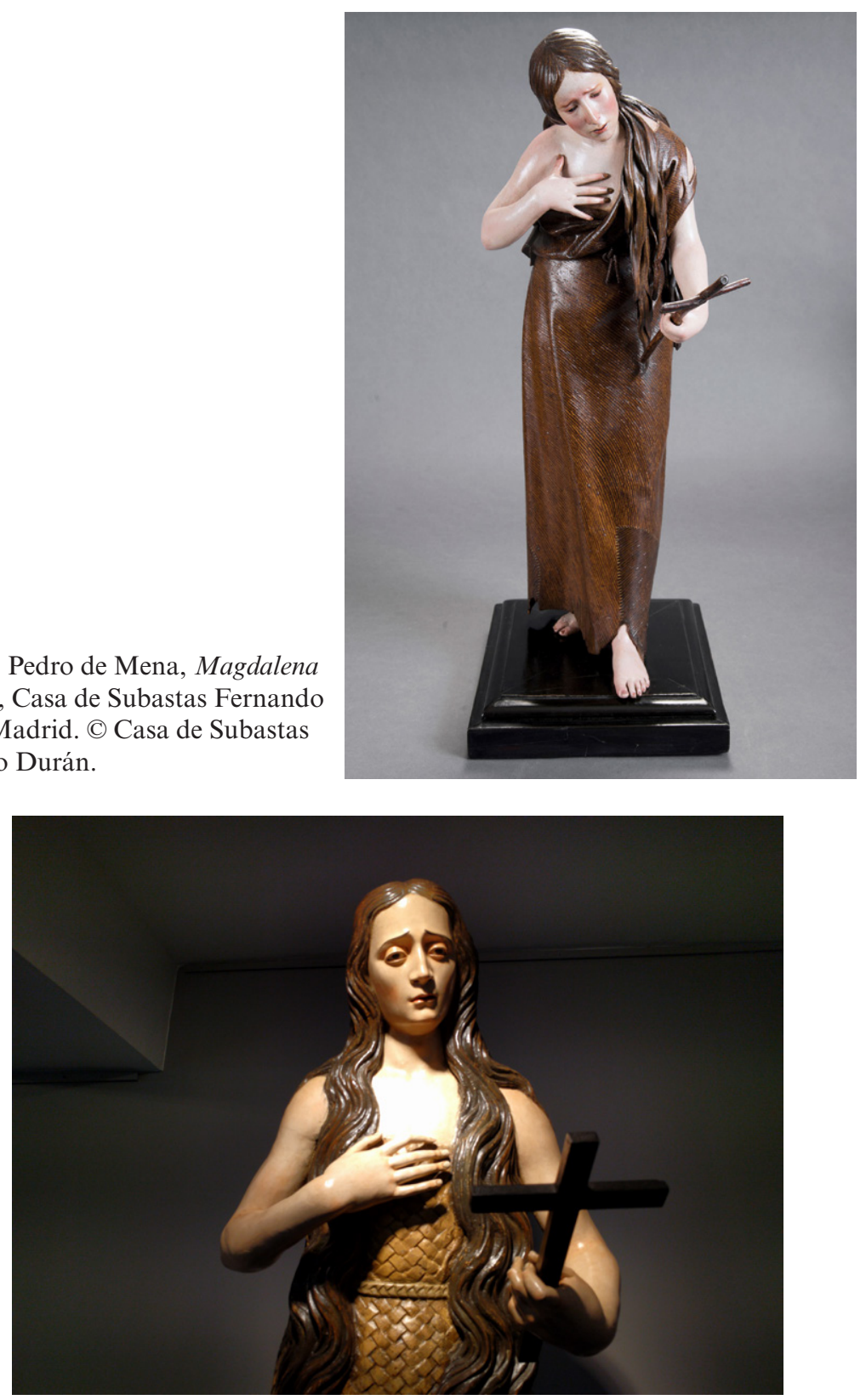

Figura 8. Atribuida a Pedro de Ávila, Magdalena penitente, hacia 1707-1740, Isbilya Subastas, Sevilla. C Daniel Puertas. 